\title{
Increased Severity of Complications After Therapeutic ERCP in Geriatric Patients With Chronic Pancreatitis: An Observational Study
}

\section{Ji-Yao Guo}

Changhai Hospital

Wen-Bin Zou

Changhai Hospital

Jia-Hui Zhu

Changhai Hospital

Nan Ru

Changhai Hospital

Jun Pan

Changhai Hospital

Yuan-Chen Wang

Changhai Hospital

\section{Yang-Yang Qian}

Changhai Hospital

Liang-Hao Hu

Changhai Hospital

Zhuan Liao ( $\sim$ liaozhuan@smmu.edu.cn )

Changhai Hospital

Zhao-Shen Li

Changhai Hospital

\section{Research Article}

Keywords: chronic pancreatitis, ERCP, geriatric, feasibility, complications

Posted Date: February 12th, 2021

DOl: https://doi.org/10.21203/rs.3.rs-183025/v1

License: (c) (i) This work is licensed under a Creative Commons Attribution 4.0 International License.

Read Full License 


\section{Abstract}

Background: Studies of therapeutic endoscopic retrograde cholangiopancreatography (ERCP) in geriatric patients have mainly examined patients with biliary diseases, rather than chronic pancreatitis (CP). This study aimed to evaluate the safety and success rate of therapeutic ERCP in geriatric patients with $C P$.

Methods: This was an observational study from prospectively collected data. The medical records of patients with CP aged over 65 years (Group A) were collected in a tertiary hospital from January 2013 to December 2018. Sex-matched CP patients under 65 years (Group B) were randomly selected into the control group (matching ratio=1:2). Collected data included demographic data, endoscopic findings, interventions, success, and complications. The success rate and the complication rate of therapeutic ERCP in two groups were compared with chi-square test. The risk factors for post-ERCP pancreatitis were investigated by univariate and multivariate analysis.

Results: A total of 268 ERCPs were performed in 179 patients of Group A and 612 ERCPs in 358 patients of Group B. The success rate of ERCP in Group A was similar to that of Group B (92.16\% vs $92.32 \%$; $P=0.936)$. The overall incidence of post-ERCP complications was $7.09 \%(19 / 268)$ and $5.72 \%(35 / 612)$ in Group $A$ and $B$, respectively $(P=0.436)$. However, geriatric patients had a significantly increased occurrence of moderate to severe complications ( $2.61 \%$ vs $0.16 \% ; P=0.002)$. Female gender $(O R=3.40$; $95 \% \mathrm{Cl}, 1.02-11.31 ; \mathrm{P}=0.046)$, pancreas divisum ( $\mathrm{OR}=7.15 ; 95 \% \mathrm{Cl}, 1.01-50.62 ; \mathrm{P}=0.049)$, dorsal pancreatogram $(\mathrm{OR}=7.40 ; 95 \% \mathrm{Cl}, 1.63-33.64 ; \mathrm{P}=0.010)$, and lithotripsy $(\mathrm{OR}=0.15 ; 95 \% \mathrm{Cl}, 0.03-0.70$; $\mathrm{P}=0.016)$ were significantly associated with risk of post-ERCP pancreatitis in geriatric patients.

Conclusions: Therapeutic ERCP is safe and feasible in elderly patients with CP. However, occurrence of moderate to severe complications after ERCP increased in geriatric patients.

Trial registration: retrospectively registered.

\section{Background}

Chronic pancreatitis (CP) is characterized by long-standing inflammation of the pancreas resulting in progressive damage to the pancreatic parenchyma; it ultimately causes failure of exocrine and endocrine pancreatic function [1,2]. The incidence of CP increases with increasing age (20-74 years), with the highest prevalence among those aged 45-74 years [3]. Due to improvements in health care, human longevity continues to rise. The World Health Organization Report 2013 highlighted the problems associated with aging of the global population [4]. Importantly, with aging of the population, more people will develop CP worldwide.

The latest guidelines recommend endoscopic retrograde cholangiopancreatography (ERCP) as the firstline therapy for patients with uncomplicated painful CP [5, 6]. Elderly patients often present with chronic concomitant diseases, such as cardiovascular diseases, respiratory diseases, and neurological diseases, 
as well as weakened body function and geriatric syndromes [7, 8]. Thus, the risk of ERCP-related adverse events may increase with age, and the consequences may be more severe and long-lasting in the elderly.

Several studies have shown that ERCP can lead to serious complications in elderly patients $[7,9,10]$, including hemorrhage, perforation, acute pancreatitis, and cholangitis, among others. Moreover, elderly patients had higher rates of chronic concomitant diseases, and the risk of complications may be associated with chronic obstructive pulmonary disease. However, there are few relevant studies in the context of $\mathrm{CP}$ and the studies that are available involve relatively small numbers of elderly $\mathrm{CP}$ patients or mixed CP patients with biliary diseases.

Thus, we conducted this study to evaluate the safety and success rate of therapeutic ERCP in CP patients aged $\geq 65$ years. The ERCP success rate and complication rate were analyzed and were compared with those of younger patients.

\section{Methods}

\section{Study design}

This study was an observational study that aimed to evaluate the outcomes of CP patients aged $\geq 65$ years who were treated with ERCP and to compare these ERCP outcomes to those of CP patients aged < 65 years. This study was approved by the Ethics Committee of Changhai Hospital and was performed in accordance with the Treaty of Helsinki. Written informed consent was obtained from all patients participating in the study.

\section{Patients and data collection}

We recruited 179 consecutive patients aged $\geq 65$ years (defined as Group A) who underwent therapeutic ERCP for the management of pancreatic stones at Changhai Hospital between January 2013 and December 2018. A total of 358 sex-matched patients with CP aged $<65$ years were recruited into the control group (defined as Group B) using the incidence density sampling method (i.e., two consecutive controls selected within one week of recruitment of one index patient) $[11,12]$, with consideration for changes in diagnostic and therapeutic modalities over time.

All patients suffered abdominal or back pain associated with pancreatitis. The diagnosis of CP was established based primarily on computed tomography, magnetic resonance imaging, or endoscopic ultrasound examinations [13-15]. Indications of ERCP were the presence of ductal stones, strictures, or both stones and strictures in the head/body of the pancreas that induced a dilated duct on imaging [16, 17]. Patients who had undergone pancreatic surgery or gastrectomy with Billroth II reconstruction prior to the ERCP procedure, who received a diagnostic-only ERCP, or who were suspected of malignant tumors were excluded from this study. A diagnostic ERCP was defined as an injection of contrast medium into the bile duct or pancreatic duct (PD) during endoscopy without any therapeutic procedure. Therapeutic ERCP was defined as any interventional procedure performed, aside from cholangiopancreatogram or 
pancreatogram. Therapeutic ERCP included endoscopic sphincterotomy, dilation of PD stricture, pancreatic stone extraction, and pancreatic stent placement $[15,18]$.

Detailed data on each patient were obtained from a prospectively maintained database. Collected data included demographic data, important chronic concomitant diseases, endoscopic findings, interventions, success, and complications. All patients were classified according to the M-ANNHEIM clinical staging [19]. Chronic concomitant diseases were classified as follows: cardiovascular (ischemic or valvular heart disease, congestive heart failure, significant cardiac arrhythmia), neurologic (previous cerebrovascular event, severe dementia, multiple sclerosis), pulmonary (chronic obstructive pulmonary disease, bronchial asthma, lung resection), diabetes mellitus, chronic renal failure, and liver cirrhosis [20].

\section{Treatment strategy}

Before performing the ERCP procedure, extracorporeal shock wave lithotripsy (ESWL) was performed for the clearance of radiopaque obstructive MPD stones larger than $5 \mathrm{~mm}$ located in the head/body of the pancreas as indicated in guidelines $[16,17]$. ESWL was performed using a third-generation electromagnetic lithotripter (Compact Delta II; Dornier Med Tech, Wessling, Germany). The patients received intravenous analgesia (flurbiprofen and remifentanil) before the procedure. One or more sessions of ESWL were performed for adequate stone fragmentation in all patients. Successful stone fragmentation after ESWL was defined as stones broken into fragments $\leq 2 \mathrm{~mm}$ or $3 \mathrm{~mm}$ or by the demonstration of a decreased stone density at x-ray, an increased stone surface, and heterogeneity of the stone that may fill the MPD and adjacent side branches [16].

Therapeutic ERCP was performed under conscious sedation with intramuscular administration of diazepam 2.5-5.0 mg and pethidine 25-50 mg. All endoscopic treatments were performed by experienced endoscopists who had each performed more than 1000 ERCP procedures. If necessary, endoscopic sphincterotomy was performed. A dilating bougie or balloon was used to dilate the stenosis after sphincterotomy. Standard techniques (i.e., extraction basket, extraction balloon, or both) were used for stone removal. A PD stent was used for drainage and nasopancreatic catheters were inserted for temporary drainage if necessary. Blood pressure, pulse, and oxygen saturation were closely monitored during all procedures. All patients were observed in the ward for 24 hours after ERCP treatment to monitor for the occurrence of complications following the intervention.

\section{Outcome measures}

There were two main outcomes of this study: the success rate of ERCP and the complication rate of ERCP. According to the classifications described by Ridtitid et al [21], ERCP can be classified as a complete success, partial success, or failure. ERCP complete success is achieved if all expected diagnostic and therapeutic measures are performed, including complete stone removal or PD drainage. ERCP is considered a partial success if only some of the expected procedures are performed successfully. If none of the planned objectives are completed, ERCP is considered a failure. 
This study also compared the ERCP complication rate in CP patients aged $\geq 65$ years with that of younger patients. Post-ERCP complications (namely bleeding, perforation, pancreatitis, infection, and basket impaction) and their severity were defined according to the Consensus Criteria reported by Cotton et al [22]. Post-ERCP pancreatitis (PEP) was defined as new or worsening abdominal pain and a serum concentration of amylase three times greater than the normal upper limit more than 24 hours after the procedure. Moreover, anaesthesia related adverse events were recorded and compared between the two groups.

\section{Statistical analyses}

Statistical analyses were performed to compare the various parameters between geriatric patients and younger patients. Depending on their distributional properties, continuous variables are expressed as mean \pm standard deviation or median and range while categorical data are expressed as percentages. Normally distributed quantitative data were analyzed with the Student's t-test. Categorical data were analyzed with the chi-square test, with Yates' correction when appropriate, or Fisher' s exact test whenever applicable. A P value (two-tailed) less than 0.05 was considered statistically significant. Variables with $\mathrm{P}<0.10$ in univariate analyses were included in multivariate logistic regression analysis using the "Enter" method. Risk factors included in the final model are presented as odds ratios (OR) with $95 \%$ confidence intervals (Cls).

\section{Results}

\section{Baseline characteristics of patients}

A total of 268 ERCP procedures were performed in 179 patients $(77.09 \%$ males) aged $\geq 65$ years (Group A). The mean age of Group A was $69.12 \pm 4.65$ years. In Group B, a total of 612 ERCP procedures were performed in 358 patients aged < 65 years (mean age $42.68 \pm 12.97$ years). There were statistically significant differences between the groups in terms of age of onset of $\mathrm{CP}$, incidence of pancreatic stones, and incidence of chronic concomitant diseases (Table 1). Compared with the control group, geriatric patients had an older age of onset of CP $(63.51 \pm 10.29$ years vs $37.63 \pm 13.71$ years; $P<0.001)$. The incidence of pancreatic stones was also higher in Group A (94.97\% vs 77.93\%; $P<0.001)$. Chronic concomitant diseases, including cardiovascular diseases $(P<0.001)$, neurologic diseases $(P=0.005)$, pulmonary diseases $(P=0.005)$, liver disease $(P=0.002)$, diabetes mellitus $(P=0.009)$, and hypertension $(P<0.001)$, were more prevalence in Group $A$ than in Group B. According to the M-ANNHEIM classification, the proportion of CP patients at stage 0 , I, II, III, IV was $5.59 \%$ vs $7.82 \%, 54.75 \%$ vs $58.10 \%, 31.84 \%$ vs $25.42 \%, 6.70 \%$ vs $7.54 \%$, and $1.12 \%$ vs $1.12 \%$ for Group $A$ and $B$, respectively (all $P>0.05$ ).

\section{ERCP findings and interventions}

Endoscopic findings on ERCP included dilation of the main pancreatic duct (MPD) in 218 (81.34\%) ERCPs, periampullary diverticula in 19 (7.09\%) ERCPs, and common bile duct (CBD) stricture in 11 (4.10\%) ERCPs (Table 2). There were no significant differences between the two groups (all $P>0.05$ ). 
Among those patients with radiopaque pancreatic stones $\geq 5 \mathrm{~mm}, 142$ (52.99\%) and $337(55.07 \%) \mathrm{ESWL}$ procedures were performed before ERCP in Group A and B, respectively $(P=0.569)$. There were $13(4.85 \%)$ and 34 (5.56\%) dorsal pancreatogram procedures in Group $A$ and $B$, respectively $(P=0.669)$. Of the six patients with pancreas divisum in Group A, five underwent dorsal pancreatogram; one did not due to failed cannulation. In both groups, major papilla sphincterotomy $(50.37 \%$ vs $52.45 \% ; P=0.570)$ and minor papilla sphincterotomy (3.36\% vs $3.92 \% ; P=0.686)$ were performed before further manipulation. In both groups, dilation of PD stricture involved bougie dilation (18.28\% vs $19.93 \% ; \mathrm{P}=0.569)$ or balloon dilation (5.97\% vs $9.48 \% ; \mathrm{P}=0.084)$. In the process of stone removal, an extraction balloon ( $64.55 \%$ vs $68.14 \% ; \mathrm{P}=$ 0.298 ) or an extraction basket (3.73\% vs $3.92 \% ; P=0.893$ ) were used. PD stents ( $5 F-10 F$ diameter) were placed in 179 (66.79\%) ERCPs in Group A and 421 (67.48\%) ERCPs in Group B ( $P=0.840)$ (Table 2).

\section{Success rate of ERCP}

The ERCP success rate was $92.16 \%(247 / 268)$ in Group A and $92.32 \%(565 / 612)$ in Group B; there was no statistically significant difference between the two groups $(P=0.936)$ (Table 3$)$. There were also no differences in complete ( $85.07 \%$ vs $84.97 \% ; P=0.967)$ or partial success $(7.09 \%$ vs $7.35 \% ; P=0.890)$ between the two groups. In Group A, there was a total of 21 ERCP failures, eight of which were caused by abnormal duodenal papilla (four due to swelling of the papilla, one due to a small opening of the papilla, and three due to no identification of the papilla). Another main reason for ERCP failure was abnormal MPD, including MPD distortion (2/21), stricture (1/21), or stone blockage (2/21). Other causes of failure included duodenal stenosis (1/21), pancreas divisum (2/21), and unknown causes (5/21).

\section{Complications of ERCP}

The overall incidence of post-ERCP complications was similar in the two groups (7.09\% vs $5.72 \%$; $\mathrm{P}=0.436)$ (Figure 1). There were no statistical differences in the incidence of PEP (4.85\% vs $4.58 \%)$, bleeding ( $1.12 \%$ vs $0.33 \%$ ), infection ( $1.12 \%$ vs $0.65 \%$ ), or basket impaction ( 0 vs $0.16 \%$ ) between the two groups (all $\mathrm{P}>0.05$ ). Although the incidence and type of complications were similar, the risk of moderate to severe complications in elderly patients was significantly increased compared to younger patients; almost all complications in Group B were mild ( $2.61 \%$ vs $0.16 \% ; P=0.002)$. All complications were resolved with conservative medical treatment, except for two cases of moderate bleeding in Group $A$.

PEP is the main post-ERCP complication. In this study, PEP was documented in 13 cases in Group A, including eight mild cases, three moderate cases, and two severe cases. In comparison, there were 28 PEPs in Group B, of which almost all were mild (27/28) and only one case of PEP was moderate. The risk of moderate to severe PEP in elderly patients was significantly higher compared to younger patients (1.87\% vs $0.16 \% ; P=0.017$ ). In Group A, no PEP occurred among CP patients at stage 0 , III, and IV, and the incidence of PEP among CP patients at stage I and II was 9.18\% (9/98) and 7.02\% (4/57), respectively. In Group B, with increasing stage, the incidence of PEP was 7.14\% (2/28), 7.69\% (16/208), 4.40\% (4/91), $3.70 \%(1 / 27)$, and $0 \%(0 / 4)$, respectively. 
Three of 268 (1.12\%) ERCP procedures in Group A developed post-ERCP bleeding. No patients with bleeding had a history of anti-platelets/anti-coagulants prior to procedure. There was one mild case of bleeding caused by pancreatic pseudocyst. The patient was treated by placing a pancreatic plastic stent for drainage of the pseudocyst in the tail of the pancreas. On the second day after ERCP, the patient presented abdominal pain. An emergency upper abdominal CT scan showed bleeding from the pseudocyst in the tail of the pancreas. The bleeding was successfully treated by intravenous injection of hemocoagulase agkistrodon. There were two moderate cases of bleeding caused by cardiac mucosal laceration. Two patients with MPD stones were treated by extraction of the stone fragments at ERCP. When the endoscopy was withdrawn, the cardiac mucosa laceration and bleeding was observed. The patients' hemoglobin levels declined significantly requiring blood transfusion treatment. For these two cases, bleeding was successfully stopped utilizing intraoperative and postoperative placement of hemostatic clips under the endoscope, hot probe hemostasis, and local injection of hemostatic drugs. There was no ERCP-related perforation or death and anaesthesia related adverse events.

\section{Risk factors for PEP}

Given the high incidence of PEP in our geriatric cohort, we performed a risk factor analysis for PEP (Table 4). Univariate analysis showed that three patient-related factors and two intervention-related factors were significantly associated with $P E P$, including female gender $(P=0.047)$, pancreas divisum $(P=0.031)$, pancreatic stones $(P=0.099)$, dorsal pancreatogram $(P=0.007)$, and $E S W L(P=0.015)$. Factors with $P$ values less than 0.10 were used to establish a multivariate model. After multivariate analysis, four factors were determined to be independently related to PEP. Female gender (OR, 3.40; 95\% $\mathrm{Cl}, 1.02-11.31$; $\mathrm{P}=0.046)$, pancreas divisum $(\mathrm{OR}, 7.15 ; 95 \% \mathrm{Cl}, 1.01-50.62 ; \mathrm{P}=0.049)$, and dorsal pancreatogram $(\mathrm{OR}, 7.40$; $95 \% \mathrm{Cl}, 1.63-33.64 ; \mathrm{P}=0.010)$ significantly increased the risk of $P E P$ and $E S W L$ prior to ERCP significantly reduced the risk of PEP (OR, 0.15; 95\% $\mathrm{Cl}, 0.03-0.70 ; \mathrm{P}=0.016)$.

\section{Discussion}

The incidence of CP increases with increasing age [3]. Thus, the need for therapeutic ERCP as a first-line treatment strategy for $\mathrm{CP}$ will continue to increase with the aging population. For this reason, it is important to recognize the risks and benefits of ERCP in geriatric patients with CP. There have been few studies of ERCP in geriatric patients and there have been none that have reported specifically on $\mathrm{CP}$ patients. Therefore, this study aimed to investigate the safety and success rate of ERCP in geriatric patients with $\mathrm{CP}$ and to explore the risk factors related to complications.

In the current study, the success rate of ERCP was found to be similar in the two groups $(92.16 \%$ vs 92.32\%; $P=0.936$ ), such that ERCP was highly feasible in elderly patients. The success rate of $92.16 \%$ in geriatric patients is similar to the success rates reported in other studies [7,23-25], which range from $88.0 \%$ to $96.9 \%$. Marianna et al [23] analyzed the clinical records of patients aged $\geq 65$ years undergoing ERCP. The main indication for ERCP was CBD stone (32.9\% vs $40.0 \%$ ) in patients aged $65-79$ years and those aged 80 years or older; the success rate of ERCP was $94.6 \%$ and $93.7 \%$, respectively. Su et al [7] 
analyzed patients 80 years of age or older and those younger than 65 years who underwent ERCP. CBD stone combined with gallbladder stone was the most common indication for ERCP (42.6\% vs $46.8 \%)$. The success rate $(94.9 \%$ vs $97.4 \% ; P=0.096)$ was not significantly different between the two groups.

The incidence of post-ERCP complications in both groups in this study was very low, at $7.09 \%$ and $5.72 \%$ for Group A and B, respectively $(P=0.436)$. The complications rate in geriatric patients was similar to those reported previously in studies that have shown that ERCP is safe for elderly patients (complications rates ranging from $4.8 \%$ to $8.4 \%$ ) $[7,24,26]$. Panagiotis et al [26] analyzed patients $\geq 90$ years and those 70 to 89 years of age who underwent ERCP. The rates of post-ERCP complications (6.3\% vs $8.4 \%$; Pख0.05) were low and not significantly different between the two groups. Fritz et al [24] analyzed the clinical records of patients $\geq 80$ years old and those $₫ 80$ years old undergoing ERCP. There was no significant difference in the complications rate between the two groups ( $6.8 \%$ vs $5.1 \%)$. One possible explanation for the lack of difference in the complications rate between the two groups is that the clinical staging of the disease, not patient age, plays a major role in the occurrence of complications. In this study, there was no difference in clinical staging between the two groups $(P>0.05)$. Further, the incidence of PEP showed a decreasing trend with increasing $\mathrm{CP}$ stage in both groups. The above hypothesis can be proved by a previous study that $\mathrm{CP}$ patients at stage la had the highest PEP incidence among all CP patients [27]. The pathophysiology behind this phenomenon may include a decrease in pancreatic enzyme secretion or further atrophy of the pancreas with disease progression and increasing clinical stage [28, 29].

Although the incidence and types of complications were similar in the two groups in this study, seven geriatric patients had moderate to severe complications while only one patient in the control group experienced moderate complications $(P=0.002)$. The risk of moderate to severe PEP in elderly patients was also significantly higher compared to younger patients. Several studies have reported similar results whereby elderly patients had increased severity of complications after ERCP [30,31]. This might be due to a physiological decline in immune system competence in the elderly compared to young patients, which increases the risk of inflammation [30]. Nonetheless, PEP can be prevented by routine rectal administration of diclofenac or indomethacin, which is recommended for all patients receiving ERCP without contraindication [32]. However, patients undergoing ERCP don't routinely receive diclofenac or indomethacin for prevention in clinical practice in China, including this study. Based on this study, elderly patients are at highest risk of moderate to severe PEP and the use of preventive drugs should be recommended prior to ERCP.

Risk factors for PEP identified in the literature include female sex, a history of acute pancreatitis or PEP, multiple cannulation attempts, and precut sphincterotomy [24, 27, 33-35]. In this study, we further confirmed that pancreatic divisum can increase the risk of PEP (OR, 7.15; 95\% Cl, 1.01-50.62; $\mathrm{P}=0.049)$. Pancreatic divisum can increase the possibility for associated operations on the accessory PD or minor papilla, including dorsal pancreatogram [36]. For this reason, dorsal pancreatogram was also significantly associated with increased risk of PEP (OR, 7.40; 95\% Cl, 1.63-33.64; $\mathrm{P}=0.010)$. 
ESWL is the standard of care for large pancreatic stones $(>5 \mathrm{~mm})$, especially for those in the head and body region $[37,38]$. The clinical guidelines state that for painful uncomplicated CP with stones $>5 \mathrm{~mm}$ in the MPD, ESWL should be the first step in management, followed by extraction of the stone fragments at a subsequent ERCP $[16,17]$. A large study of 5124 patients with CP who underwent ESWL and ERCP, of whom 548 patients were $>60$ years of age, confirmed the safety and efficacy and short-term pain relief of ESWL for large calculi in the MPD [39]. In addition to helping to remove large stones that were not amenable for extraction by ERCP, our analysis showed that patients with prior ESWL had a significantly lower risk of PEP $(\mathrm{OR}, 0.15 ; 95 \% \mathrm{Cl}, 0.03-0.70 ; \mathrm{P}=0.016)$. This is probably due to the reduced difficulty of cannulation following ESWL.

There are several limitations of this study that should be noted. Firstly, we could not evaluate the longterm therapeutic effects of ERCP due to a lack of enough follow-up data after patient discharge. Secondly, all procedures were performed by experienced endoscopists, and thus, our results may not be generalizable to other contexts. Thirdly, the definition of ERCP success is considered somewhat subjective in this study and may be a confounding factor in these results. Nonetheless, it should be considered that there are no widely accepted definitions of complete success, partial success, or failure.

\section{Conclusions}

In conclusion, this is the first study to compare the safety and success rate of therapeutic ERCP in elderly patients and younger patients suffering from CP. The success rate of therapeutic ERCP in elderly patients with $\mathrm{CP}$ was identical to that of younger patients. However, in comparison to younger patients, occurrence of moderate to severe complications after therapeutic ERCP increased in geriatric patients, although there was no obvious difference in the overall incidence of complications between the two groups. This study indicates that therapeutic ERCP is safe and feasible in elderly patients with CP. However, there is a need for improved awareness of the severity of complications among geriatric patients; this may be of benefit in perioperative management of these patients. In the future, there is a need for the development of assessment tools to make careful periprocedural assessment of ERCP risks in elderly patients, in order to predict and prevent the occurrence of complications.

\section{Abbreviations}

$\mathrm{CBD}$, common bile duct; $\mathrm{Cl}$, confidence intervals; $\mathrm{CP}$, chronic pancreatitis; ERCP, endoscopic retrograde cholangiopancreatography; ESWL, extracorporeal shock wave lithotripsy; MPD, main pancreatic duct; OR, odds ratios; PD, pancreatic duct; PEP, post-ERCP pancreatitis.

\section{Declarations}

Ethics approval and consent to participate 
The study involving human participants has been approved by Changhai Institutional Review Board and has been performed in accordance with the ethical standards laid down in the 1964 Declaration of Helsinki and its later amendments. All patients gave the informed consent for analysis of the medical records during hospitalization.

\section{Consent for publication}

Not applicable.

\section{Availability of data and materials}

The datasets used and/or analysed during the current study are available from the corresponding author on reasonable request.

\section{Competing interests}

The authors declare that they have no competing interests.

\section{Funding}

Support for this study came from the National Natural Science Foundation of China (Grant No. 81770636[Z.L.], 81873588[Z.S.L.], 81700565 [W.B.Z.]), the Scientific Innovation Program of Shanghai Municipal Education Committee [Z.L.], and Shanghai Sailing Program (Grant No. 18YF1422800[J.P.]), China. The recipients of the fund, Wen-Bin Zou revised the manuscript, Jun Pan played a role in data analysis, and Zhuan Liao and Zhao-Shen Li designed the study.

\section{Authors' contributions}

JYG, WBZ, ZSL and ZL had full access to all of the data in the study and take responsibility for the integrity of the data and the accuracy of the data analysis. ZSL and ZL contributed to study supervision. JYG, WBZ, ZSL and ZL contributed to study concept and design. JYG, WBZ and JHZ drafted the manuscript and carried out the statistical analysis. NR, JP, YCW, YYQ and LHH played a role in acquisition, analysis, or interpretation of data. All authors approved the final version of the manuscript.

\section{Acknowledgements}

Not applicable.

\section{References}

1. Majumder S, Chari ST. Chronic pancreatitis. Lancet. 2016;387:1957-66.

2. Zou WB, Ru N, Wu H, et al. Guidelines for the diagnosis and treatment of chronic pancreatitis in China (2018 edition). Hepatobiliary Pancreat Dis Int. 2019;18:103-109. 
3. Petrov MS, Yadav D. Global epidemiology and holistic prevention of pancreatitis. Nat Rev Gastroenterol Hepatol. 2019;16:175-184.

4. Organization WH. The world health report 2013. Bmj. 2013;328:6.

5. Dumonceau JM, Delhaye M, Tringali A, et al. Endoscopic treatment of chronic pancreatitis: European Society of Gastrointestinal Endoscopy (ESGE) Guideline - Updated August 2018. Endoscopy. 2019;51:179-193.

6. Lohr JM, Dominguez-Munoz E, Rosendahl J, et al. United European Gastroenterology evidence-based guidelines for the diagnosis and therapy of chronic pancreatitis (HaPanEU). United European Gastroenterol J. 2017;5:153-199.

7. Han SJ, Lee TH, Kang Bl, et al. Efficacy and Safety of Therapeutic Endoscopic Retrograde Cholangiopancreatography in the Elderly Over 80 Years. Dig Dis Sci. 2016;61:2094-101.

8. Holt BA. Increased severity of post-endoscopic retrograde cholangiopancreatography complications in the elderly: an issue to be addressed. Dig Endosc. 2014;26:534-5.

9. Katsinelos P, Kountouras J, Chatzimavroudis G, et al. Outpatient therapeutic endoscopic retrograde cholangiopancreatography is safe in patients aged 80 years and older. Endoscopy. 2011;43:128-33.

10. Ukkonen M, Siiki A, Antila A, et al. Safety and Efficacy of Acute Endoscopic Retrograde Cholangiopancreatography in the Elderly. Dig Dis Sci. 2016;61:3302-3308.

11. Talagala IA, Nawarathne M, Arambepola C. Novel risk factors for primary prevention of oesophageal carcinoma: a case-control study from Sri Lanka. BMC Cancer. 2018;18:1135.

12. Ru N, He CH, Ren $X L$, et al. Risk factors for sinistral portal hypertension and related variceal bleeding in patients with chronic pancreatitis. J Dig Dis. 2020;21:468-474.

13. Zou WB, Tang XY, Zhou DZ, et al. SPINK1, PRSS1, CTRC, and CFTR Genotypes Influence Disease Onset and Clinical Outcomes in Chronic Pancreatitis. Clin Transl Gastroenterol. 2018;9:204.

14. Gardner TB, Adler DG, Forsmark CE, et al. ACG Clinical Guideline: Chronic Pancreatitis. Am J Gastroenterol. 2020;115:322-339.

15. Kichler A, Jang S. Chronic Pancreatitis: Epidemiology, Diagnosis, and Management Updates. Drugs. 2020;80:1155-1168.

16. Dumonceau JM, Delhaye M, Tringali A, et al. Endoscopic treatment of chronic pancreatitis: European Society of Gastrointestinal Endoscopy (ESGE) Guideline - Updated August 2018. Endoscopy. 2019;51:179-193.

17. Löhr JM, Dominguez-Munoz E, Rosendahl J, et al. United European Gastroenterology evidence-based guidelines for the diagnosis and therapy of chronic pancreatitis (HaPanEU). United European Gastroenterol J. 2017;5:153-199.

18. Li ZS, Wang W, Liao Z, et al. A long-term follow-up study on endoscopic management of children and adolescents with chronic pancreatitis. Am J Gastroenterol. 2010;105:1884-92.

19. Schneider A, Lohr JM, Singer MV. The M-ANNHEIM classification of chronic pancreatitis: introduction of a unifying classification system based on a review of previous classifications of the disease. $J$ 
Gastroenterol. 2007;42:101-19.

20. Hu L, Sun X, Hao J, et al. Long-term follow-up of therapeutic ERCP in 78 patients aged 90 years or older. Sci Rep. 2014;4:4918.

21. Bernica J, Elhanafi S, Kalakota N, et al. Cholangioscopy Is Safe and Feasible in Elderly Patients. Clin Gastroenterol Hepatol. 2018;16:1293-1299.e2.

22. Cotton PB, Lehman G, Vennes J, et al. Endoscopic sphincterotomy complications and their management: an attempt at consensus. Gastrointest Endosc. 1991;37:383-93.

23. Galeazzi M, Mazzola P, Valcarcel B, et al. Endoscopic retrograde cholangiopancreatography in the elderly: results of a retrospective study and a geriatricians' point of view. BMC Gastroenterol. 2018;18:38.

24. Fritz E, Kirchgatterer A, Hubner D, et al. ERCP is safe and effective in patients 80 years of age and older compared with younger patients. Gastrointest Endosc. 2006;64:899-905.

25. Lukens FJ, Howell DA, Upender S, et al. ERCP in the very elderly: outcomes among patients older than eighty. Dig Dis Sci. 2010;55:847-51.

26. Katsinelos P, Paroutoglou G, Kountouras J, et al. Efficacy and safety of therapeutic ERCP in patients 90 years of age and older. Gastrointest Endosc. 2006;63:417-23.

27. Zhao ZH, Hu LH, Ren HB, et al. Incidence and risk factors for post-ERCP pancreatitis in chronic pancreatitis. Gastrointest Endosc. 2017;86:519-524.e1.

28. Schmitz-Moormann P, Himmelmann GW, Brandes JW, et al. Comparative radiological and morphological study of human pancreas. Pancreatitis like changes in postmortem ductograms and their morphological pattern. Possible implication for ERCP. Gut. 1985;26:406-14.

29. Laugier R, Bernard JP, Berthezene P, et al. Changes in pancreatic exocrine secretion with age: pancreatic exocrine secretion does decrease in the elderly. Digestion. 1991;50:202-11.

30. Nishikawa T, Tsuyuguchi T, Sakai Y, et al. Old age is associated with increased severity of complications in endoscopic biliary stone removal. Dig Endosc. 2014;26:569-76.

31. Glomsaker T, Hoff G, Kvaloy JT, et al. Patterns and predictive factors of complications after endoscopic retrograde cholangiopancreatography. Br J Surg. 2013;100:373-80.

32. Dumonceau JM, Andriulli A, Elmunzer BJ, et al. Prophylaxis of post-ERCP pancreatitis: European Society of Gastrointestinal Endoscopy (ESGE) Guideline - updated June 2014. Endoscopy. 2014;46:799-815.

33. Rabenstein T, Schneider HT, Bulling D, et al. Analysis of the risk factors associated with endoscopic sphincterotomy techniques: preliminary results of a prospective study, with emphasis on the reduced risk of acute pancreatitis with low-dose anticoagulation treatment. Endoscopy. 2000;32:10-9.

34. Freeman ML, DiSario JA, Nelson DB, et al. Risk factors for post-ERCP pancreatitis: a prospective, multicenter study. Gastrointest Endosc. 2001;54:425-34.

35. Masci E, Toti G, Mariani A, et al. Complications of diagnostic and therapeutic ERCP: a prospective multicenter study. Am J Gastroenterol. 2001;96:417-23. 
36. Stefanidis G, Viazis N, Pleskow D, et al. Large balloon dilation vs. mechanical lithotripsy for the management of large bile duct stones: a prospective randomized study. Am J Gastroenterol. 2011;106:278-85.

37. Guda NM, Partington S, Freeman ML. Extracorporeal shock wave lithotripsy in the management of chronic calcific pancreatitis: a meta-analysis. Jop. 2005;6:6-12.

38. Costamagna G, Gabbrielli A, Mutignani M, et al. Extracorporeal shock wave lithotripsy of pancreatic stones in chronic pancreatitis: immediate and medium-term results. Gastrointest Endosc. 1997;46:231-6.

39. Tandan M, Nageshwar Reddy D, Talukdar R, et al. ESWL for large pancreatic calculi: Report of over 5000 patients. Pancreatology. 2019;19:916-921.

\section{Tables}




\begin{tabular}{|c|c|c|c|}
\hline & $\begin{array}{l}\text { Geriatric group } \\
(\mathrm{n}=179)\end{array}$ & $\begin{array}{l}\text { Control group } \\
(n=358)\end{array}$ & $\begin{array}{l}P \\
\text { value }\end{array}$ \\
\hline Male, n (\%) & $138(77.09 \%)$ & $276(77.09 \%)$ & 1 \\
\hline Age at enrollment (years) & $69.12 \pm 4.65$ & $42.68 \pm 12.97$ & $<0.001$ \\
\hline $\begin{array}{l}\text { Age at onset of chronic } \\
\text { pancreatitis (years) }\end{array}$ & $63.51 \pm 10.29$ & $37.63 \pm 13.71$ & $<0.001$ \\
\hline Prior acute pancreatitis, $\mathrm{n}(\%)$ & $115(64.25 \%)$ & $240(67.04 \%)$ & 0.519 \\
\hline Pancreatic stones, n (\%) & $170(94.97 \%)$ & $279(77.93 \%)$ & $<0.001$ \\
\hline Steatorrhea, n (\%) & $25(13.97 \%)$ & $59(16.48 \%)$ & 0.450 \\
\hline Pancreas divisum, n (\%) & $6(3.35 \%)$ & $16(4.47 \%)$ & 0.538 \\
\hline \multicolumn{4}{|c|}{ Chronic concomitant diseases, n (\%) } \\
\hline n Cardiovascular & $18(10.06 \%)$ & $5(1.40 \%)$ & $<0.001$ \\
\hline n Neurologic & $9(5.03 \%)$ & $3(0.84 \%)$ & 0.005 \\
\hline n Pulmonary & $13(7.26 \%)$ & $8(2.23 \%)$ & 0.005 \\
\hline n Renal & $3(1.68 \%)$ & $3(0.84 \%)$ & 0.663 \\
\hline n Liver & $15(8.38 \%)$ & $9(2.51 \%)$ & 0.002 \\
\hline n Diabetes mellitus & $62(34.64 \%)$ & $86(24.02 \%)$ & 0.009 \\
\hline n Hypertension & $61(34.08 \%)$ & $36(10.06 \%)$ & $<0.001$ \\
\hline \multicolumn{4}{|l|}{$\begin{array}{l}\text { M-ANNHEIM clinical } \\
\text { staging, } n(\%)\end{array}$} \\
\hline n 0 & $10(5.59 \%)$ & $28(7.82 \%)$ & 0.341 \\
\hline n I & $98(54.75 \%)$ & $208(58.10 \%)$ & 0.460 \\
\hline$n \quad I$ & $57(31.84 \%)$ & $91(25.42 \%)$ & 0.116 \\
\hline n III & 12 (6.70\%) & 27 (7.54\%) & 0.724 \\
\hline $\mathrm{n}$ IV & $2(1.12 \%)$ & $4(1.12 \%)$ & 1.000 \\
\hline
\end{tabular}


Table 2 Findings and Interventions of all Endoscopic Retrograde cholangiopancreatography Procedures

$\begin{array}{lll}\text { Geriatric group } & \text { Control group } & P \\ (n=268) & (n=612) & \text { value }\end{array}$

Endoscopic findings, $\mathrm{n}(\%)$

\begin{tabular}{llll} 
n MPD dilation & $218(81.34 \%)$ & $520(84.97 \%)$ & 0.179 \\
\hline $\mathrm{n}$ Periampullary diverticula & $19(7.09 \%)$ & $32(5.23 \%)$ & 0.277 \\
\hline $\mathrm{n}$ CBD stricture & $11(4.10 \%)$ & $13(2.12 \%)$ & 0.097 \\
\hline ESWL procedure, $\mathrm{n}(\%)$ & $142(52.99 \%)$ & $337(55.07 \%)$ & 0.569 \\
\hline Difficult cannulation, $\mathrm{n}(\%)$ & $47(17.54 \%)$ & $99(16.18 \%)$ & 0.617 \\
\hline Dorsal pancreatogram, $\mathrm{n}(\%)$ & $13(4.85 \%)$ & $34(5.56 \%)$ & 0.669 \\
\hline Endoscopic papillotomy, $\mathrm{n}(\%)$ & & & \\
\hline $\mathrm{n}$ Major & $135(50.37 \%)$ & $321(52.45 \%)$ & 0.570 \\
\hline $\mathrm{n}$ Minor & $9(3.36 \%)$ & $24(3.92 \%)$ & 0.686
\end{tabular}

Pancreatic duct stricture

dilation, $\mathrm{n}(\%)$

\begin{tabular}{|c|c|c|}
\hline $\mathrm{n}$ Bougie dilation & 49 (18.28\%) & $122(19.93 \%)$ \\
\hline $\mathrm{n}$ Balloon dilation & $16(5.97 \%)$ & $58(9.48 \%)$ \\
\hline
\end{tabular}

Stone extraction, $\mathrm{n}(\%)$

\begin{tabular}{llll}
$\mathrm{n}$ by balloon & $173(64.55 \%)$ & $417(68.14 \%)$ & 0.298 \\
$\mathrm{n}$ by basket & $10(3.73 \%)$ & $24(3.92 \%)$ & 0.893 \\
\hline Pancreatic stent, $\mathrm{n}(\%)$ & $179(66.79 \%)$ & $413(67.48 \%)$ & 0.840 \\
\hline Stent diameter (F), n (\%) & & & \\
$\mathrm{n} 5$ & $79(29.48 \%)$ & $144(23.53 \%)$ & 0.062 \\
$\mathrm{n} 7$ & $75(27.99 \%)$ & $186(30.39 \%)$ & 0.572 \\
$\mathrm{n} 8.5$ & $19(7.09 \%)$ & $64(10.46 \%)$ & 0.116 \\
$\mathrm{n} 10$ & $6(2.24 \%)$ & $19(3.10 \%)$ & 0.477
\end{tabular}

MPD, main pancreatic duct; CBD, common bile duct; ESWL, extracorporeal shock wave lithotripsy. 


\begin{tabular}{|c|c|c|c|}
\hline & $\begin{array}{l}\text { Geriatric group } \\
(n=268)\end{array}$ & $\begin{array}{l}\text { Control group } \\
(n=612)\end{array}$ & $\begin{array}{l}\mathrm{P} \\
\text { value }\end{array}$ \\
\hline Success, n (\%) & 247 (92.16\%) & 565 (92.32\%) & 0.936 \\
\hline n Complete $^{+}$ & $228(85.07 \%)$ & $520(84.97 \%)$ & 0.967 \\
\hline n Partial ${ }^{\ddagger}$ & $19(7.09 \%)$ & $45(7.35 \%)$ & 0.890 \\
\hline Failure $\S, n(\%)$ & $21(7.84 \%)$ & $47(7.68 \%)$ & 0.936 \\
\hline \multicolumn{4}{|c|}{${ }^{\dagger}$ All expected diagnostic and therapeutic measures are performed. } \\
\hline
\end{tabular}


Table 4 Univariate and Multivariate Analysis of Factors Affecting Incidence of PEP in Geriatric Patients With CP

Variables

Univariate

OR $\quad 95 \% \mathrm{Cl}$
Multivariate

Pvalue OR $\quad 95 \% \mathrm{Cl} \quad P$ value

Patient factors $(n=179)$

Female gender

$3.21 \quad 1.01-10.16$

0.047

3.40

1.02-11.31

0.046

Pancreatic divisum

$7.32 \quad 1.21-44.45$

0.031

7.15

1.01-50.62

0.049

Pancreatic stones

0.24

0.05-1.31

0.099

Prior acute

$1.27 \quad 0.38-4.31$

0.698

pancreatitis

Intervention factors $(n=268)$

$\begin{array}{lllllll}\text { ESWL } & 0.15 & 0.03-0.69 & 0.015 & 0.15 & 0.03-0.70 & 0.016\end{array}$

Difficult cannulation

0.77

0.17-3.58

0.743

Dorsal

7.35

1.75-30.92

0.007

7.40

1.63-33.64

0.010

pancreatogram

\begin{tabular}{llll} 
Endoscopic papillotomy & 1.40 & $0.45-4.40$ & 0.564 \\
\hline Dilation of stricture & 1.48 & $0.44-4.97$ & 0.529
\end{tabular}

PEP, post-ERCP pancreatitis; $\mathrm{CP}$, chronic pancreatitis; OR, odds ratio; $\mathrm{Cl}$, confidence interval; ESWL, extracorporeal shock wave lithotripsy.

\section{Figures}

A Type of Post-ERCP Complication

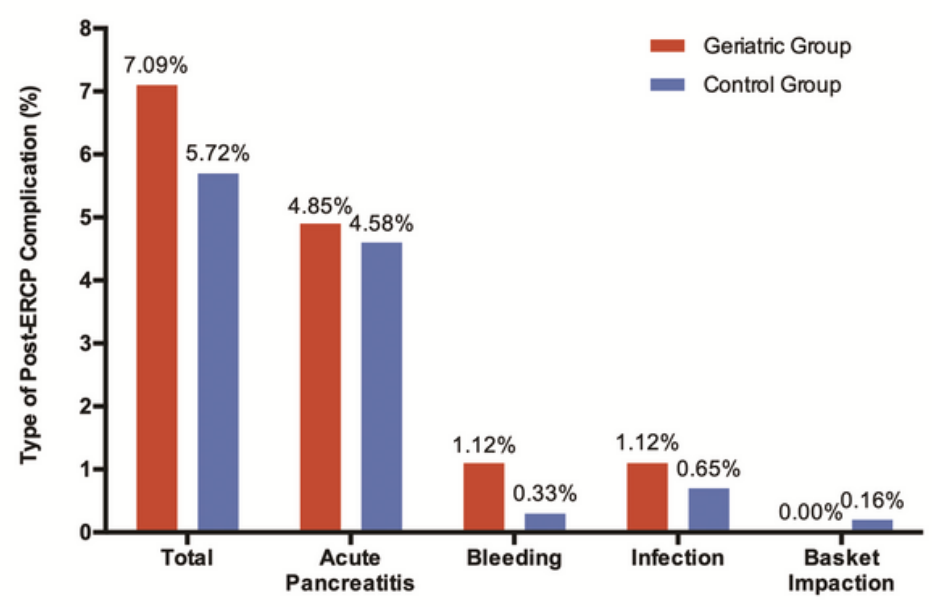

B Severity of Post-ERCP Complication

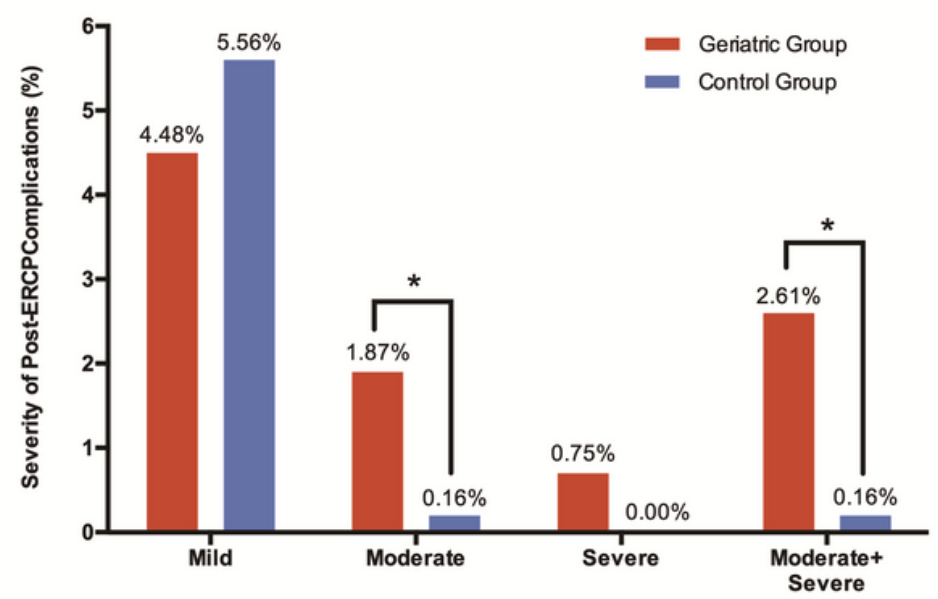




\section{Figure 1}

Comparison of Type (A) and Severity (B) of Post-ERCP Complications Between Geriatric and Control Group. * $P<0.05$. ERCP, endoscopic retrograde cholangiopancreatography. 